\title{
Global Climate Implications for Homelessness: A Scoping Review
}

\author{
Sean A. Kidd (iD $\cdot$ Susan Greco $•$ Kwame McKenzie
}

Accepted: 4 September 2020 / Published online: 23 September 2020

(C) The New York Academy of Medicine 2020

\begin{abstract}
Homelessness is a persistent global challenge with significant health impacts on those affected. Homeless people are by definition the most exposed to weather conditions and the social and economic problems caused by extreme weather and climate change and variability. This systematic review was designed to synthesize the academic literature that addresses the health and social implications of global climate change for homelessness. The question examined in this systematic scoping review is the following: What is the current state of knowledge in the scientific literature on the health and social implications of global climate change for homelessness? A systematic scoping review method was used to identify and synthesize the peer-reviewed literature relevant to this question. The databases searched were PsycINFO, Medline, Scopus, and Google Scholar. Of the 26 papers identified in this review, 20 employed original data analyses with conclusions largely inferred from cross-sectional associations. Themes included the potential influence of climate change on homelessness
\end{abstract}

S. A. Kidd $\cdot$ K. McKenzie

Department of Psychiatry, University of Toronto, Toronto, Canada

S. A. Kidd $(\bowtie)$

Division Chief - Psychology, Centre for Addiction and Mental Health, 1001 Queen St. W., Unit 2-1, \#161, Toronto, Ontario M6J 1H4, Canada

e-mail: sean_kidd@camh.net

S. Greco

Dalla Lana School of Public Health, University of Toronto, Toronto, Canada prevalence, climate impacts that exacerbate specific vulnerabilities of homeless populations (e.g., chronic illness, exposure, stigmatization), and health and social outcomes. Service use and design implications were also addressed. Given the scale of the impacts of climate change on homelessness, the literature on this topic poses promising directions but is under-developed in its current state to adequately inform risk mitigation and response planning. A systems framework is proposed here to inform future research and service design.

Keywords Homelessness $\cdot$ Climate $\cdot$ Review $\cdot$ Systems

Global climate change has been described as "the defining issue of our time" [44]. Climate refers to weather parameters such as temperature, rainfall, and wind speed that occur in a given place over a given period of time [46]. However, such a general definition belies the complexity of the phenomenon and the dangers that it poses [12]. To date, large volumes of evidence describe and predict the potential adverse effects of climate change [7]. In this literature, human health and social impacts figure prominently. Extremes of temperature, coupled with humidity levels, significantly impact mortality rates as do extreme weather events $[18,21]$. Temperature and humidity also influence illness morbidity (e.g., respiratory and cardiovascular conditions) [17], and have implications for the progression of vector-borne diseases [33], with differential risks as a function of age with risk increasing at the youngest and oldest ends of the spectrum $[3,11]$. The social impacts of climate extremes and 
changes include pronounced impacts on rates of interpersonal and intergroup violence [22], social and health infrastructure [8], and migration [4]. A cross-cutting theme of these various interactions is inequality - with disproportionately larger effects on the lives of the impoverished and stigmatized who also increase in number due to climate impacts. Gender figures prominently with climate effects disproportionately higher for girls and women in all domains (e.g., mortality, HIV infection, education) [7].

Homelessness, in turn, is a persistent global challenge with major health impacts on those affected. It is estimated that over 100 million people are homeless globally, with 1 billion living in precarious housing arrangements [43]. Homeless people are by definition the most exposed to weather conditions and the social and economic problems caused by extreme weather and climate change. The umbrella term "homelessness" belies a dimensional construct [14] ranging from being roofless and sleeping rough, being houseless in shelter environments, through to various forms of insecure and inadequate housing - all of which have unique implications as they relate to climate change and weather exposure. Thus, it is important to consider the possible consequences of climate change for homeless populations. This topic has, to date, received relatively little attention and preparedness for the impacts of a changing climate on homelessness populations is in question. Accordingly, this systematic review was designed to synthesize the academic literature that addresses the health and social implications of global climate change for homelessness.

\section{Methods}

Scoping review methods are designed to identify and articulate concepts and evidence in areas where the topic of investigation is complex and (or) when the topic is reviewed for the first time. Global climate change is complex in terms of types of impact, systems involved, and the associated fields of study. Furthermore, we did not identify a previous systematic review that addresses this topic. As such, we have followed the Arksey and O'Malley [2] five-stage scoping review framework of (1) identifying the research question, (2) identifying relevant results, (3) selecting studies, (4) charting data, and (5) reporting results. Our description of the scoping review design was further informed by Levac et al. [29].
The authors of the present review have expertise in homelessness (SK), population health and marginality (KM), and the public health implications of weather and climate change (SG).

First, the question examined in this review is as follows: What is the current state of knowledge in the scientific literature on the health and social implications of global climate change for homelessness? The breadth of this question was necessary due to the early stage of the literature on this topic. Second, an a priori search strategy was developed to identify the peer-reviewed literature relevant to this question. The search, conducted in November 2019, covered the period from inception to November 2019, and was restricted to English language peer-reviewed journals. The databases searched were PsycINFO, Medline, Scopus, and Google Scholar. The resulting search terms included for group one: "homeless*" and "climate", "weather", or "environment*". Keywords were searched using "OR" within groups and "AND" in two separate searches to combine homelessness and keywords relevant to the climate change phenomenon. For Google Scholar, the search proceeded until 100 unsuccessful hits occurred after the last successful hit in the identified documents. In stage 3 , we examined abstracts to ensure that they focused on climate and homelessness. We excluded papers at the abstract review level that did not address this combined topic and removed duplicates. We included papers that involved data collection and papers that did not (e.g., commentaries) given the early stage of the literature in this area and expert commentaries' potential value. We also included papers that did not overtly address global climate change as the implications of those papers would seem relevant. A full-text review was completed of all articles selected through the abstract review (extracted by SK), with some further removal of papers that were out of scope and some additional identification of papers from reference lists. We charted $[2,38]$ the selected papers based upon (i) basic descriptors (e.g., year and country of publication, publication type, and method), (ii) a summary of the findings of studies involving data, and (iii) a thematic synthesis [30] of both research and commentary jointly interpreting the thematic analysis framework which was developed using the original text from the identified papers. Findings were summarized as a function of both coverage of key themes and methods used with a consensus process determining the research, policy, and practice implications of the findings. The consultation 
phase [29] of this program of work, of which the present review is the first step, will take place in a subsequent stage. That phase will involve the use of a Delphi method [23] to engage international experts in the field who will develop policy guidance based on their experience, the present review, and a review of reviews (underway) examining the climate change-related housing implications for impoverished populations.

\section{Results}

The search results are detailed in Fig. 1. PsycINFO generated 1420 results, which, in turn, were reduced to 873 when limited to English language and peerreviewed journals. Medline yielded 942 results that were reduced to 898 when limited to English. Scopus generated 517 results, and Google Scholar generated 7880 results. Of the papers identified in the search, 43 articles were selected as meeting the search criteria after removing duplicates $(n=21)$. Additional 4 articles were identified from reference lists. The full texts of these 47 papers were then reviewed, with 21 subsequently removed as not meeting criteria, leaving 26 for which their content was charted (Table 1). The 26 included publications spanned the years 1998 to 2019 (Fig. 2). The majority were authored in the USA $(n=13)$, followed by Australia $(n=4)$ and Canada $(n=4)$, with single papers from Poland, Nigeria, India, the UK, and Venezuela. Twenty-one papers involved data collection with the remainder consisting of commentaries and narrative reviews (none systematic). Of the 21 research papers, 15 were quantitative, 5 were qualitative, and one used mixed methods.

None of the identified papers provided causal data that links global climate change with a change in homelessness prevalence, morbidity, or mortality. The effects of climate change were typically inferred from observations of the associations between weather and the experiences and outcomes of homeless persons. The degree to which climate change was addressed varied. Some papers concentrated solely on the effects of weather extremes upon homelessness and change over time, without overtly addressing global climate change [47]. The earliest paper that described climate change and homelessness directly was authored by Ramin and Svoboda in 2009. The proportions of papers that directly addressed climate change versus weather impacts alone are shown in Fig. 2. The impacts of temperature extremes and climate change on homelessness were viewed almost without exception as negative. Only one paper made some conjectures about the possible benefits of climate change for some homeless populations (e.g., those residing in Canada). Ramin and Svoboda [37] noted that in generally colder climates, warmer weather may lead to fewer deaths from cold exposure and illnesses such as influenza, with the caveat that risks may outweigh these benefits. There was also considerable variability across papers regarding how the construct of homelessness was defined. Five papers, primarily commentaries, provided no clear definition and used the term broadly, and 7 papers relied upon a homeless categorization derived from electronic medical records or administrative data sets with little detail on definition aside from the indication of no fixed abode or similar. Six papers concentrated on shelter-using populations, with service use status as the indicator of homelessness, and 5 papers described their populations as having experienced "absolute" or "primary" homelessness with some variability as how this categorization addressed (i.e., sleeping rough (roofless) or some emergency shelter use). These latter papers tended to address the dimensionality of homelessness to a greater degree (e.g., [45]), with Every et al. [13] applying the European Typology of Homelessness and Housing Exclusion definition of degrees of homelessness and housing precarity. The most nuanced commentary on homelessness as dimensional and intertwined with social inequities described these phenomena in low income countries where it was argued that housing precarity and homelessness must be considered differently than the situations in high income countries [1, 47].

This review is organized into four themes as they emerged in the thematic synthesis. First is the topic of weather and climate change as a driver of homelessness prevalence. The second theme addresses how the conditions of homelessness serve to increase vulnerability to weather extremes. The third theme addresses the role of extreme weather and variability in the health of homeless populations. The fourth theme addresses service access and design.

Weather and Climate Change and the Prevalence of Homelessness

This literature provided little data-derived information about how weather and climate change may serve as a driver of increasing homeless numbers. This topic was 
generally addressed with broad statements about largescale risks inferred from climate data [16], with some emphasizing unique vulnerabilities faced in low-income countries (e.g., "The phenomenon of climate change heralds distinctive challenges for sub-Saharan Africa's urban areas, with economic, social, and health impacts, and severe effects on housing and infrastructure." [1], p.15; [47]). An exception was Every et al. [13], wherein a survey of homeless sector service providers in Australia indicated an estimate that extreme weather was a pathway to homelessness for $16.2 \%$ of service users.

\section{Vulnerability and Exposure}

The topic of vulnerability was addressed primarily through commentary that emphasized the weather exposure risks (both temperature and extreme weather events such as flooding) that are greatly heightened for the homeless [16, 41, 45]. This theme was highlighted across settings internationally, including the Arctic and icecap melting [34]. A case study of Lagos, Nigeria, highlighted the flood and broader weather exposure risks for slum dwellers and squatters that result from both the quality and location of their dwellings [1], with similar themes addressed by Wiesenfeld and Panza [47] in Venezuela regarding vulnerability to landslides. Papers addressing low-income contexts concentrated on severe poverty and the challenges of very marginally housed individuals who are more exposed and less able to recover from extreme weather events. While most of this literature concentrated on physical exposure, qualitative US research emphasized that exposure is an intersectional phenomenon that includes not just greater exposure to the elements but also intersects with factors such as social stigma and unemployment [40].

Chronic health conditions common to homeless populations create unique and increased vulnerability to conditions such as heat stroke, dehydration, and respiratory illness [13]. Malnourishment was referenced as a problem that reduced the capacity to tolerate cold exposure [45]. Also, the risk of death from heat is increased for those with psychiatric disabilities, alcoholism, and cognitive impairment - inferring risk from the high prevalence of these conditions among the homeless [37].

Access to means for mobility and social resources were also highlighted as exacerbating exposure to weather extremes. Authors commented on homeless persons' limited ability to escape extreme weather and draw upon social resources in emergencies [13]. Social isolation, common among the homeless, was also flagged as a risk factor for death from extreme heat [37] as was public access to water which is increasingly privatized in urban environments [19]. Finally, some commentary addressed the impacts of climate change
Fig. 1 Article selection flow diagram

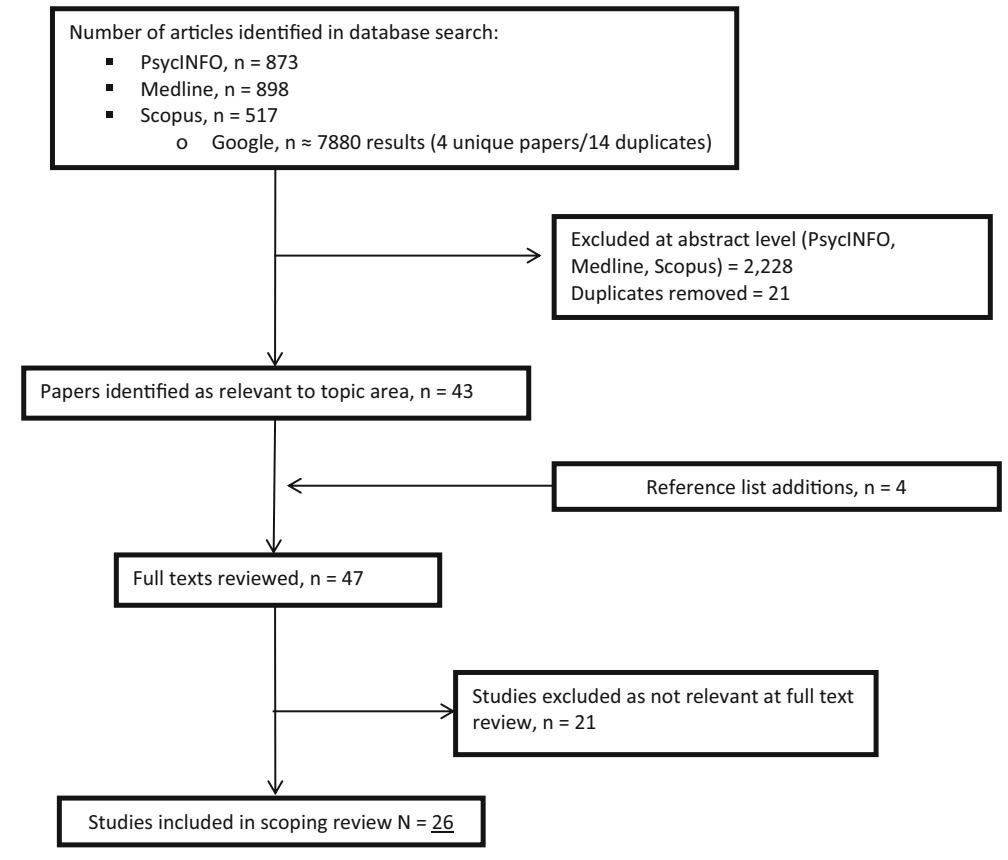


on food security, with the homeless being particularly vulnerable [6].

Some commentaries placed this increased exposure to climate-related risks among the homeless in the context of the "environmental injustices" experienced by this population [16]. These authors highlight the systemic inequities and discrimination that homeless people face which, in turn, both increase exposure to

Table 1 Article summary

\begin{tabular}{l}
\hline Paper \\
\hline Hale [19]. Fountains for environmental justice: public water, homelessness, and migration \\
in the face of global environmental change. \\
Zhang et al. [48]. Cold weather conditions and risk of hypothermia among people experiencing \\
homelessness: implications for prevention strategies. \\
*Gibson [16]. Climate change for individuals experiencing homelessness: recommendations for \\
improving policy, research, and services. \\
Every et al. [13]. There's nowhere to go: counting the costs of extreme weather to the homeless community. \\
Corinth and Lucas [9]. When warm and cold do not mix: the implications of climate for the \\
$\quad$ determinants of homelessness. \\
Romaszko et al. [39]. Mortality among the homeless: causes and meteorological relationships. \\
Settembrino [40]. "Sometimes You Cannot Even Sleep at Night:" social vulnerability to \\
$\quad$ disasters among men experiencing homelessness in Central Florida. \\
Nicolay et al. [32]. A study of heat related illness preparedness in homeless veterans.
\end{tabular}

Quilty et al. [36]. Factors contributing to frequent attendance to the emergency department Australia of a remote Northern Territory hospital.

Lee et al. [27]. Geographic distribution of disaster-specific emergency department use after Hurricane Sandy in New York City.

Adetokunbo and Emeka [1]. Urbanization, housing, homelessness and climate change.

*Campbell [6]. Let us not forget climate change in the food insecurity conversation: why the homeless are most vulnerable.

Walters and Gaillard [45]. Disaster risk at the margins: homelessness, vulnerability and hazards.

Siordia et al. [42]. A geographically-aware multilevel analysis on the association between atmospheric temperature and the "Emergency and transitional shelter population".

Pepper and Jocoy [35]. A climatological analysis of emergency homeless shelter openings in Long Beach, California, USA.

Cusack et al. [10]. Extreme weather-related health needs of people who are homeless.

Harlan et al. [20]. Neighborhood effects on heat deaths: social and environmental predictors of vulnerability in Maricopa County, Arizona.

*Parlee and Furgal [34]. Well-being and environmental change in the arctic: a synthesis of selected research from Canada's International Polar Year program.

*Shonkoff et al. [41]. The climate gap: environmental health and equity implications of climate change and mitigation policies in California - a review of the literature.

Klein and Riemer [24]. Experiences of environmental justice and injustice in communities of people experiencing homelessness.

Brown et al. [5]. Do emergency department attendances by homeless people increase in cold weather?.

Kloos et al. [25]. Investigating the roles of neighborhood environments and housing-based social support in the relocation of persons made homeless by hurricane Katrina.

*Ramin and Svoboda [37]. Health of the homeless and climate change.

USA

Nigeria

Australia

India

USA

USA

Australia

USA

Canada

USA

Canada

UK

USA

USA

Canada

Venezuela

Wiesenfeld and Panza [47]. Environmental hazards and home loss: the social construction of becoming homeless.

North et al. [31]. The association of psychiatric diagnosis with weather conditions in a large urban homeless sample.

*Primarily review and/or commentary

Number of articles identified in database search: PsycINFO, $n=873$; Medline, $n=898$; Scopus, $n=517$; Google, $n \approx 7880$ results (4 unique papers/14 duplicates) 
environmental risks and decrease access to assistance for the negative outcomes of those risks [16, 19]. However, homeless people themselves may be less likely to hold this perspective [24].

\section{Climate Change, Weather, and Health Outcomes}

The health outcome risks that were associated with weather events were the area with the most quantitative data. In both Canada [26, 48] and Poland [39], heightened cold-related morbidity and mortality were observed for homeless populations, and both moderately cold and extremely cold temperatures present significant risks. Zhang et al. [48] also demonstrated health outcome risks related to increases in precipitation. Harlan et al. [20] described heat-related mortality in Arizona, noting that the mortality risk for homeless persons was particularly concentrated in the inner core and industrial corridor areas. They wrote of a "heat island" effect in which higher temperatures are observed in places where a large majority of homeless people seek shelter [37]. Another US study in this area described homeless individuals' experiences, noted minimal recognition of the symptoms of heat-related illness aside from dizziness [32]. In an Australian study of homeless service provider impressions about the impacts of extreme weather [13], providers saw extreme weather events as negatively affecting the physical health of $18 \%$ of their clients, the mental health of $37 \%$, and the drug and alcohol consumption of $26 \%$. This study's qualitative suggested that weather-related stressors such as the restriction of movement and disrupted social connections due to loss and evacuation create and compound mental health challenges. These observations were reflected in another qualitative study done in Australia in which the most physical and mental suffering was ascribed to extremely cold and wet weather-mainly due to wet bedding,

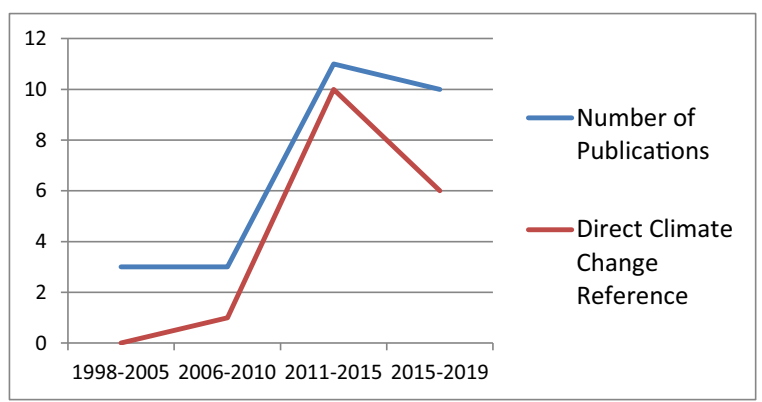

Fig. 2 Histogram of climate change and homelessness publications (1998-2019) clothing, and shoes [10]. Similarly, a US study observed greater rates of diagnoses of mental illnesses and addictions among homeless men when diagnostic interviews took place on days with cold and wet weather in St. Louis [31].

Finally, one study of Australian service provider perspectives suggested that interpersonal violence, as a key health determinant, is strongly affected by extreme weather for homeless populations. In this survey, providers attributed interpersonal violence and domestic violence to extreme weather at rates of $26.5 \%$ and $18.5 \%$, respectively, suggesting that this increase was likely due to people unexpectedly being placed in close quarters for extended periods [13]. The only additional point in this area was that of Ramin and Svoboda [37]. They suggested the increased risk of water- and vectorborne illness for more exposed homeless populations in reference to both rising sea levels and extreme weather events.

\section{Services and Service Access}

With respect to weather and service use, an Australian study suggested a modest relationship between frequent emergency service use by homeless persons in hotter, wetter weather [36], with a UK study finding no difference in general emergency department use by homeless persons as a function of cold weather [5]. Another US study noted a greater likelihood of emergency department use by homeless persons in weather emergencies such as hurricanes [27]. It was also suggested that transience and many homeless persons' hidden locations hamper emergency response workers efforts in climate emergencies [13]. This may be a problem compounded by a lack of environmental emergency planning related to homeless populations [45].

Quantitative research examined ambient temperature as it related to emergency shelter availability. First, across the USA, it was observed that the numbers/ concentrations of emergency and temporary shelter users were positively associated with warmer climate regions [42]. Another study examined the periods of emergency shelter operation in California against days with low temperature or rain and concluded that periods of operation adequately aligned with weather conditions, though noted that providers seemed primarily concerned with extreme heat relative to cold [35]. While research into the outcomes of interventions in this area was lacking, several authors made 
recommendations for service and system improvements. Suggestions included the education of homeless populations about the symptoms of heat-related illness [32], improved access to public water fountains [19], land use zoning and water management strategies to reduce exposure [1], and developing improved host strategies for individuals made homeless by natural disasters [25]. Finally, there was some commentary on how underfunding and poor planning adversely impacts the response to climate-exposed homeless populations in both an ongoing way and during disasters $[13,16]$.

\section{Tentative Model for Considering}

Climate-Homelessness Interrelationships

Overall, this literature has several shortcomings, particularly due to the lack of data that might address causal relationships between homelessness, weather impacts, and climate change. However, there would seem to be enough information at hand, even if purely hypothetical at this stage, to posit a model that might capture the most substantive variables and their respective influences (Fig. 3). In this model the primary (e.g., increasing temperature and temperature variability) and secondary (e.g., water insecurity) impacts of climate change are moderated by variables that are specific to vulnerably housed and homeless populations from individual to system levels (e.g., chronic respiratory illness, malnutrition, location vulnerability, service planning, response, and infrastructure). The interactions between weatherrelated risks and variables that characterize homeless populations will determine outcomes at individual (e.g., mortality, violence exposure), system (e.g., emergency service use), and population levels (e.g., homelessness prevalence and migration). This model is supported in the literature reviewed, wherein the possibility of variable impacts as a function of specific climate stressors and moderators such as chronic illness on health and social outcomes was documented [13, 39]. What is attempted here, and what seemed to have yet to happen in the modest literature to date, is to organize these posited variables and relationships into a single framework. Much more hypothetical are possible feedback loops such as how outcomes might affect moderators over time from individual to population levels and, potentially, how outcomes such as mass homelessness and migration might themselves impact climate change.

\section{Discussion}

This systematic scoping review found that the literature addressing the health and social impacts of weather and climate change on homelessness is limited to a small number of commentaries and analyses of primarily local, cross-sectional data. Nonetheless, it can be inferred from the small amount of data generated to date and the consideration of the nature of climate change, weather, and homelessness as conditions that homeless populations face unique vulnerabilities. These vulnerabilities likely lead to serious mental and physical health consequences. Furthermore, the prevalence of homelessness globally may be increasing due to the climate and weather vulnerabilities of marginally housed people. Based on this review, we have proposed a model that might capture this phenomenon (Fig. 3). While much more data would be necessary to validate this model, it is well-aligned with climate risk modeling initiatives underway that are grappling with multiple interactions and dynamic change from geographic to social levels over time [15].
Fig. 3 Hypothetical model for considering climate-homelessness relationships

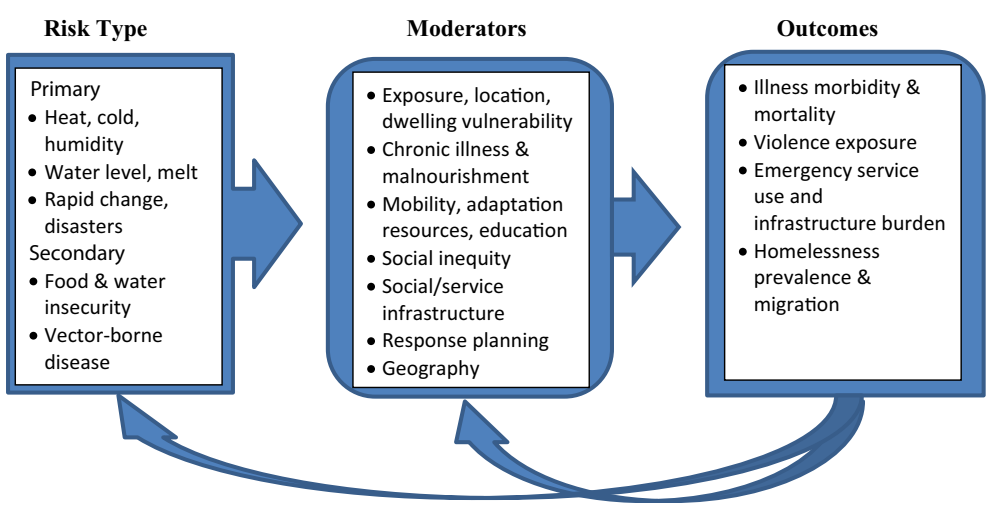


The generation of risk mitigation and response strategies could, in turn, be developed and optimized with more robust risk modeling data. It is conceivable that a risk algorithm could help service systems and geographic regions develop multilevel and multistage approaches. For example, a given service system might become able to employ, with better evidence, more effective prevention, and risk mitigation strategies for specific homeless subpopulations as it relates to particular weather risks. Systems might also become better able to prepare for increases in numbers of homeless people due to extreme weather events. Prevention efforts might also be informed by feedback loops. Hypothetical examples include increased exposure to violence leading to an avoidance of services and the exacerbation of weather-related problems such as vector-borne disease. With some exceptions [16], the literature to date has not substantively explored systematic responses - responses that are beginning to emerge globally in the broader frame such as the Resilient Cities Program [28]. However, there are promising initial steps addressed in this review that might become a part of a systemic response. Examples in the literature reviewed include outreach and education for homeless and vulnerable populations [32], provider education [10], service adaptations and disaster planning [16]. Such strategies might be further developed using a model such as the one proposed in the present review. The model could inform how best to combine and sequence responses as a function of stage (current state-projected future states, risk mitigation, and prevention-crisis response) with contingencies to attend the dynamic and complex nature of climate impacts. More generally, as a function of homeless people as a highly stigmatized group, this review has highlighted the perspective that climate impacts on homelessness may exacerbate systematic and historical inequities along intersecting socioeconomic, racial, and cultural lines [7, 16, 34].

In conclusion, this scoping review has highlighted a potential model for considering the health and social risks that global climate change pose for homeless populations. The review must be regarded as preliminary, given the ranging foci and methods described in the identified papers. There is also ambiguity in how degrees of homelessness versus highly vulnerable housing are considered and the influences of geographic context, with relatively little coverage of phenomena relevant to low and middle-income countries where weather vulnerabilities are the most acute. From research to the design of service and system responses, clear articulation of degrees of homelessness/housing vulnerability (e.g., [14]) and the systemic inequities that they represent will be essential. Nonetheless, the themes highlighted in this review might serve to guide future studies that can address some of the knowledge gaps that reduce our collective ability to respond to this global problem.

\section{References}

1. Adetokunbo I, Emeka M. Urbanization, housing, homelessness and climate change. J Des Built Env. 2015;15(2):15-28.

2. Arksey H, O’Malley L. Scoping studies: towards a methodological framework. Int J Social Res Meth. 2005;8(1):19-32.

3. Åström DO, Bertil F, Joacim R. Heat wave impact on morbidity and mortality in the elderly population: a review of recent studies. Maturitas. 2011;69(2):99-105.

4. Bohra-Mishra P, Oppenheimer M, Hsiang SM. Nonlinear permanent migration response to climatic variations but minimal response to disasters. Proc Natl Acad Sci. 2014;111(27):9780-5.

5. Brown AJ, Goodacre SW, Cross S. Do emergency department attendances by homeless people increase in cold weather? Emerg Med J. 2010;27(7):526-9.

6. Campbell S. Let's not forget climate change in the food insecurity conversation: why the homeless are most vulnerable. Health Promot J Aust. 2015;26(2):161-2.

7. Carleton TA, Hsiang SM. Social and economic impacts of climate. Science. 2016;353(6304):aad9837.

8. Chappin EJ, van der Lei T. Adaptation of interconnected infrastructures to climate change: a socio-technical systems perspective. Util Policy. 2014;31:10-7.

9. Corinth K, Lucas DS. When warm and cold don't mix: the implications of climate for the determinants of homelessness. J Hous Econ. 2018;41:45-56.

10. Cusack L, van Loon A, Kralik D, Arbon P, Gilbert S. Extreme weather-related health needs of people who are homeless. Aust J Prim Health. 2013;19(3):250-5.

11. Deschênes O, Greenstone M, Guryan J. Climate change and birth weight. Am Econ Rev. 2009;99(2):211-7.

12. Dessai S, Adger WN, Hulme M, Turnpenny J, Köhler J, Warren R. Defining and experiencing dangerous climate change. Clim Chang. 2004;64(1-2):11-25.

13. Every D, Richardson J, Osborn E. There's nowhere to go: counting the costs of extreme weather to the homeless community. Disasters. 2019;43(4):799-817.

14. FEANTSA. European Typology of Homelessness and Housing Exclusion. https://www.feantsa. org/download/ethos2484215748748239888.pdf (Accessed June 24, 2020).

15. Gallina V, Torresan S, Critto A, Sperotto A, Glade T, Marcomini A. A review of multi-risk methodologies for natural hazards: consequences and challenges for a climate change impact assessment. J Environ Manag. 2016;168: 123-32. 
16. Gibson A. Climate change for individuals experiencing homelessness: recommendations for improving policy, research, and services. Environ Just. 2019;12:159-63.

17. Gronlund CJ, Sullivan KP, Kefelegn Y, Cameron L, O’Neill MS. Climate change and temperature extremes: a review of heat-and cold-related morbidity and mortality concerns of municipalities. Maturitas. 2018;114:54-9.

18. Guo Y, Gasparrini A, Armstrong B, Li S, Tawatsupa B, Tobias A, et al. Global variation in the effects of ambient temperature on mortality: a systematic evaluation. Epidemiology. 2014;25(6):781-9.

19. Hale MR. Fountains for environmental justice: public water, homelessness, and migration in the face of global environmental change. Envir Justice. 2019;12(2):33-40.

20. Harlan SL, Declet-Barreto JH, Stefanov WL, et al. Neighborhood effects on heat deaths: social and environmental predictors of vulnerability in Maricopa County, Arizona. Environ Health Perspect. 2012;121(2):197-204.

21. Hsiang SM, Narita D. Adaptation to cyclone risk: evidence from the global cross-section. Clim Change Econ. 2012;3(02):1250011.

22. Hsiang SM, Burke M, Miguel E. Quantifying the influence of climate on human conflict. Science. 2013;341(6151): 1235367.

23. Jorm AF. Using the Delphi expert consensus method in mental health research. Aust NZ J Psychiat. 2015;49(10): 887-97.

24. Klein K, Riemer M. Experiences of environmental justice and injustice in communities of people experiencing homelessness. Ecopsychol. 2011;3(3):195-204.

25. Kloos B, Flory K, Hankin BL, Cheely CA, Segal M. Investigating the roles of neighborhood environments and housing-based social support in the relocation of persons made homeless by hurricane Katrina. J Prev \& Interv Comm. 2009;37(2):143-54.

26. Koutsavlis AT, Kosatsky T. Environmental-temperature injury in a Canadian metropolis. J Environ Health. 2003;66(5):40-5.

27. Lee DC, Smith SW, Carr BG, Doran KM, Portelli I, Grudzen CR, et al. Geographic distribution of disasterspecific emergency department use after hurricane Sandy in New York City. Disaster Med Public. 2016;10(3):35161.

28. Leitner H, Sheppard E, Webber S, Colven E. Globalizing urban resilience. Urban Geogr. 2018;39(8):1276-84.

29. Levac D, Colquhoun H, O'Brien KK. Scoping studies: advancing the methodology. Implement Sci. 2010;5(1):69.

30. Ring N, Ritchie K, Mandava L, Jepson R. A guide to synthesising qualitative research for researchers undertaking health technology assessments and systematic reviews. Glasgow: Quality Improvement Scotland (NHS QIS); 2010.

31. North CS, Pollio DE, Thompson SJ, Spitznagel EL, Smith EM. The association of psychiatric diagnosis with weather conditions in a large urban homeless sample. Soc Psychiatry Psychiatr Epidemiol. 1998;33(5):206-10.

32. Nicolay M, Brown LM, Johns R, et al. A study of heat related illness preparedness in homeless veterans. Int $J$ Disast Risk Re. 2016;18:72-4.

33. Ogden NH. Climate change and vector-borne diseases of public health significance. FEMS Microbiol Lett. 2017;364(19):fnx186.
34. Parlee B, Furgal C. Well-being and environmental change in the arctic: a synthesis of selected research from Canada's international polar year program. Clim Chang. 2012;115(1): 13-34.

35. Pepper DA, Jocoy CL. A climatological analysis of emergency homeless shelter openings in Long Beach, California, USA. Appl Geogr. 2013;37:168-75.

36. Quilty S, Shannon G, Yao A, Sargent W, McVeigh MF. Factors contributing to frequent attendance to the emergency department of a remote Northern Territory hospital. Med $J$ Aust. 2016;204(3):111-111.e7.

37. Ramin B, Svoboda T. Health of the homeless and climate change. J Urban Health. 2009;86(4):654-64.

38. Ritchie J, Spencer L. Qualitative data analysis for applied policy research by Jane Ritchie and Liz Spencer. In: Bryman A, Burgess RG, editors. Analysing Qualitative Data. London: Routledge; 1994. p. 173-94.

39. Romaszko J, Cymes I, Dragańska E, Kuchta R, GlińskaLewczuk K. Mortality among the homeless: causes and meteorological relationships. PLoS One. 2017;12(12): e0189938.

40. Settembrino MR. "Sometimes You Can't Even Sleep at Night:" social vulnerability to disasters among men experiencing homelessness in Central Florida. Int J Mass Emerg Disasters. 2017;35(2):30-48.

41. Shonkoff SB, Morello-Frosch R, Pastor M, Sadd J. The climate gap: environmental health and equity implications of climate change and mitigation policies in California-a review of the literature. Clim Chang. 2011;109(1):485-503.

42. Siordia C, Smith C, Castañeda-Tinoco E. A geographicallyaware multilevel analysis on the association between atmospheric temperature and the emergency and transitional shelter population. Hum Geograph-J Stud Res Human Geograph. 2014;8(2)

43. United Nations (2005) Commission on human rights annual report - 2005 . https://w w w o h c hr. org/EN/Issues/Housing/Pages/AnnualReports.aspx. Accessed January 3, 2020.

44. United Nations (2020) https://www.un. org/en/sections/issues-depth/climate-change/ Accessed January 3, 2020.

45. Walters V, Gaillard JC. Disaster risk at the margins: homelessness, vulnerability and hazards. Habitat Int. 2014;44: 211-9.

46. Werndl C. On defining climate and climate change. Brit $J$ Phil Sci. 2016;67(2):337-64.

47. Wiesenfeld E, Panza R. Environmental hazards and home loss: the social construction of becoming homeless. Community Work Fam. 1999;2(1):51-65.

48. Zhang P, Wiens K, Wang R, Luong L, Ansara D, Gower S, et al. Cold weather conditions and risk of hypothermia among people experiencing homelessness: implications for prevention strategies. Int $J$ Environ Res Pub Health. 2019;16(18):3259.

Publisher's Note Springer Nature remains neutral with regard to jurisdictional claims in published maps and institutional affiliations. 